\title{
MÍDIA, MERCADORIZAÇÃO ESPORTIVA E O MOVIMENTO DE POPULARIZAÇÃO DO MMA
}

\author{
Vamberto Ferreira Miranda Filho \\ Universidade do Estado da Bahia, Salvador, Bahia, Brasil. \\ Igor Sampaio Pinho dos Santos \\ Universidade do Estado da Bahia, Salvador, Bahia, Brasil.
}

\begin{abstract}
Resumo
Este estudo tem por objetivo analisar a relação entre mídia e esporte no processo de popularização do $M M A$ na sociedade, num contexto que tem como ordem econômico-social o capitalismo. Inicialmente, buscou-se estabelecer uma discussão com a literatura, no sentido de compreender o fenômeno esportivo e como ele se configura na sociedade contemporânea. Essa etapa, eminentemente teórica, forneceu subsídios para elucidar alguns questionamentos que permeiam o veemente crescimento do fenômeno $M M A$ e sua constante evidência nos meios de comunicação de massa. Como resultado, verificou-se que a popularização do $M M A$ na sociedade está atrelada à persuasão da mídia, mediante o processo de mercadorização esportiva.
\end{abstract}

Palavras chave: Mídia. MMA. Mercadorização Esportiva. Popularização.

\section{Introdução}

A sociedade hodierna, também conhecida como "sociedade da informação e do espetáculo", é regida por interesses ideológicos que visam, única e exclusivamente, fins lucrativos. É também marcada por grandes avanços tecnológicos em que os meios de comunicação de massa, coagidos pelo sistema capitalista, exercem considerável influência na disseminação de informações, manipulando a consciência dos seus receptores mediante a espetacularização das manifestações culturais, cujo objetivo é o consumo. Dentre os meios de comunicação destacam-se a TV e a Internet, atuando soberanas, influenciando um grande número de pessoas simultaneamente.

O esporte, considerado uma das mais significativas manifestações socioculturais da atualidade, adquiriu uma estreita relação com a mídia e esta, por sua vez, passou a interferir decisivamente na disseminação de informações sobre o discurso esportivo, definindo a visão de esporte que deve ser passada para a sociedade. Com isso, o esporte tornou-se uma espécie de 
espetáculo, sendo transformado num dos maiores produtos de consumo predominantemente viabilizado no mundo inteiro.

Como exemplo dessa espetacularização da mídia, destaca-se o Mixed Martial Arts (MMA), um esporte de combate que surgiu nos Estados Unidos (EUA) na década de 1990 e que tem adquirido constante destaque nos meios de comunicação de massa, sendo considerado como um dos esportes que mais crescem em evidência, adquirindo um relevante número de admiradores a cada dia.

Alvarez e Marques (2011) afirmam que o termo MMA surgiu no início dos anos 2000 substituindo o antigo Vale-Tudo que, outrora, era promovido, desde os anos de 1920, em terras brasileiras pela família Gracie. Através das transmissões dos combates, mediante os canais de TV, o referido esporte tornou-se mundialmente conhecido, adquirindo constante evidência na mídia.

Ao reconhecer o MMA como um dos esportes que mais crescem em evidência na mídia e considerando a escassez de estudos na Educação Física que tratem cientificamente desse assunto, o objetivo central deste trabalho é preencher essa lacuna e fornecer elementos que ajudem a compreender o que permeia a popularização do $M M A$ em nossa sociedade e de que maneira a mídia tem contribuído para esse processo.

\section{Mídia e MMA: uma relação pautada no consumo das massas.}

Mídia, para o senso comum, resume-se apenas aos meios de comunicação de massa. Entretanto, de acordo alguns estudiosos como Pires (2000), mídia não somente refere-se aos meios de comunicação de massa (rádio, televisão, jornal, internet, etc.), como ao conjunto de empresas que produzem e mercadorizam informações, entretenimento e publicidade, de acordo os seus interesses na cultura do consumo.

Para Betti (1998), a palavra mídia tem origem do latim media, plural de medium, o que significa meio, e ele a entende como meio de comunicação de massa que permite a comunicação simultânea entre um grande número de pessoas. É também entendida como uma indústria produtora e veiculadora de símbolos e significados socialmente compartilhados na cultura contemporânea.

Complementando, Pires (2000) caracteriza a sociedade hodierna como a "sociedade da informação", marcada por uma realidade forjada

Pensar a Prática, Goiânia, v. 17, n. 3, p. 865-877, jul./set. 2014 
e que vive em função de uma ideologia pregada pela indústria da comunicação de massa, ou Indústria Cultural ${ }^{1}$.

Nesse processo de ideologia, a mídia utiliza diversas manobras estratégicas, dentre elas a alienação em massa, mediante uma semiformação cultural destinada à espetacularização e ao consumo, configurando-se com grande domínio, direcionando suas mensagens para os sujeitos receptores, estabelecendo formas e padrões culturais, provocando a atrofia da imaginação do consumidor, não lhe permitindo qualquer atividade mental (ADORNO e HORKHEIMER, 1985).

O esporte aparece nesse contexto como parceiro preferencial da mídia no processo de espetacularização na sociedade contemporânea. Isso pode estar relacionado ao forte apelo e mobilização social presentes na estrutura do esporte e por ele estar presente na vida da maioria das pessoas, sendo considerado um fenômeno expressivo da cultura humana, apresentando-se, inclusive, com múltiplas dimensões: com caráter econômico, cultural, social, político e ideológico (BRACHT, 2005).

Segundo Betti (1998), a televisão e a internet, devido à abrangência na disseminação de suas mensagens, atuam como principais mecanismos nesse esquema, influenciando um grande número de pessoas simultaneamente. Ainda de acordo com este autor, essa associação vem alterando de maneira rápida e progressiva a prática do esporte e a percepção que se tem dele atualmente.

Pires (2000) afirma que a mídia amplia conceitos do esporte na tentativa de induzir o seu consumo na sociedade. Acrescentando, Leite (2008, p. 02) afirma que "o esporte tem sua manutenção efetivada através da influência da mídia, que não está apenas envolvida na sua transmissão, mas também na produção, transformação e ressignificação".

Nesse contexto, percebe-se a relevância dada ao esporte pela indústria midiática, com destaque para o sensacionalismo dos jornais e programas esportivos, atribuindo-lhe diversas características, dentre elas o esporte espetáculo como possibilidade de ascensão social, mediante a idolatria e exposição dos atletas "heróis", valorizados pelos feitos no meio esportivo ou pelo prestígio da fama e do dinheiro. Aliada ao capitalismo, a mídia utiliza a figura do atleta campeão como "protótipo" de sucesso para incutir sua ideologia na mente dos indivíduos.

O termo Indústria Cultural surgiu em 1947, a partir da obra clássica Dialética do Esclarecimento, de Theodor W. Adorno e Max Horkheimer, pensadores da Escola de Frankfurt, para substituir a expressão cultura de massa na sociedade ocidental. Para esses autores, no início do século XX, o cinema, o rádio e a televisão ganharam notório destaque e se dedicaram, em grande parte, a homogeneizar os padrões da cultura.

Pensar a Prática, Goiânia, v. 17, n. 3, p. 865-877, jul./set. 2014 
[...] o Capitalismo impõe que as pessoas estejam sempre buscando a melhoria de sua situação financeira. Sendo assim, o papel da mídia é mostrar e idolatrar alguns pouquíssimos atletas que conseguem obter sucesso através do esporte e fazer com que estes passem a servir como modelos para outros milhões de pessoas que tentarão em vão este mesmo sucesso (LEITE, 2008, p. 02).

São estereótipos criados pela mídia, falsas necessidades para influenciar e alienar a sociedade, espetacularizando o esporte e fomentando o seu consumo. Para se estabelecer com mais domínio, a mídia, através da convergência dos meios de comunicação ${ }^{2}$, conforme afirma Pires (2000, p. 22), "alcança quase todos os recantos e cidadãos do globo", transformando esporte espetáculo num dos maiores produtos de consumo, predominantemente viabilizado no mundo inteiro.

O esporte é visto como uma espécie de produto que recebe o tratamento necessário para ser comercializado pelos meios de comunicação, e isso acontece nas mais variadas formas para gerar audiência e lucro. Com isso, cresceu o interesse comercial da indústria capitalista pelo "fenômeno" esportivo. Este foi transformado em tele-espetáculo e, de acordo Betti (1998), modelado para ser consumido por telespectadores que procuram um entretenimento excitante. Nesse contexto, surge um novo fenômeno: o $\mathrm{Mi}$ xed Martial Arts (MMA), estimado como um dos esportes que mais crescem em notoriedade no mundo.

O termo Mixed Martial Arts (MMA), utilizado hoje, significa Artes Marciais Mistas, surgiu no início dos anos 2000 e era antes conhecido como Vale-Tudo, devido aos combates sem regras estabelecidas. É composto por um conjunto de artes marciais (jiu-jitsu, o muay thai, o karatê, kick boxing, o boxe, o wrestling), onde não é necessário dominar apenas um estilo de arte marcial, exclusivamente. Nesse caso, durante um combate, o praticante pode utilizar dos inúmeros recursos que a referida prática disponibiliza. Nos dias atuais, o MMA tem como principal evento promotor de suas lutas o Ultimate Fighting Championship (UFC).

\footnotetext{
2 A convergência dos meios de comunicação é consequência dos diversos avanços tecnológicos na área da comunicação, prometendo uma maior democratização de conteúdos informativos e encurtando distâncias, permitindo maior interação do homem moderno em sociedade. Pode ser considerado um marco na história dos meios de comunicação de massa, onde várias mídias como a TV, o rádio, a internet e os canais de telefonia digital se aliam na busca da ampliação e diversificação dos mercados consumidores.
}

Pensar a Prática, Goiânia, v. 17, n. 3, p. 865-877, jul./set. 2014 
O surgimento desse novo fenômeno esportivo, de acordo com Alvarez e Marques (2011), está atrelado à trajetória dos Gracie na tentativa de difundir a prática do brazilian jiu-jitsu ${ }^{3}$. Com isso, o referido esporte de combate chegou ao conhecimento de todo o mundo a partir de 1993, nos Estados Unidos, ainda como Vale-Tudo, e fora criado para ser um espetáculo esportivo na TV a cabo pelo pay-per-view.

No início do ano 2000, o $M M A$ passou por uma série de mudanças, cujo primeiro passo foi a busca pela sua regulamentação, culminando na eliminação do termo Vale-Tudo, o que denotava uma ideia de atividade violenta, e passou a ter regras bem definidas, tornando-se uma prática esportivizada. Após a sua esportivização, o $M M A$ ganhou mais evidência e tornou-se um fenômeno midiático, conquistando uma legião de fãs em todo o mundo (ALVAREZ e MARQUES, 2011).

Porém, a popularização do $M M A$ no Brasil é algo recente. Pressupõe-se que a sua veiculação tornou-se mais efetiva a partir das transmissões ao vivo das lutas pela TV a cabo, no canal Combate, e pela TV aberta, através da emissora brasileira Rede TV, que reproduzia os compactos das principais lutas no programa UFC Sem Limites. Porém, acredita-se que foi a partir do UFC Rio, transmitido pela Rede Globo no dia 12 de novembro de 2011, que o $M M A$ ganhou maior visibilidade na mídia brasileira. O evento alcançou altos picos de audiência na emissora e o esporte de combate foi destacado pelo apresentador e narrador Galvão Bueno como: "um esporte novo, que ganha mais espaço a cada dia, com milhões de adeptos e fãs por todo o mundo" (TOREZANI, 2012, p. 03).

O MMA, assim como outras modalidades esportivas, tornou-se "um objeto significativo, uma janela para a compreensão de nosso atual momento, marcado por uma profunda crise identitária e permeado pelas tecnologias de informação" (ALVAREZ e MARQUES, 2011, p. 08). O esporte que conhecemos hoje foge da compreensão de consciência e prática corporal, enquanto experiência individual ou coletiva, para se tornar uma "prática" ori-

3

O MMA era antes conhecido como Vale-Tudo e foi criado no Brasil na década de 1930 pela família Gracie, com o objetivo de mostrar a superioridade técnica da arte marcial difundida entre o clã: o jiu-jitsu Gracie, também conhecido como brazilian jiu-jitsu. Os Gracie se dedicaram a uma incrível peregrinação pelo Brasil, desafiando vários lutadores de outras artes marciais, a fim de provar a superioridade do jiu-jitsu brasileiro. Com o intuito de popularizar a referida arte marcial nos Estados Unidos, Rorion Gracie passa a desafiar lutadores de várias artes marciais para confrontos praticamente sem regras, daí surge a denominação Vale-Tudo. Todas as lutas eram filmadas e televisionadas na TV a cabo. A popularidade de Rorion e do jiu-jitsu brasileiro começou a crescer e a ganhar evidência nos EUA e, consequentemente, ganhou popularização, dando fama internacional ao sobrenome da família no mundo.

Pensar a Prática, Goiânia, v. 17, n. 3, p. 865-877, jul./set. 2014 
entada por interesses midiatizados, garantindo o motor desse grande esquema da sociedade vigente: o consumo.

\section{Mercadorização esportiva: implicações na popularização do $M M A$}

O termo mercadorização esportiva é utilizado por muitos teóricos, como Bracht (2005), para explicar o processo de transformação que vem ocorrendo no campo da cultura esportiva. Mercadorização é sinônimo de mercantilização e significa comércio. Nesse caso, compreende-se a mercadorização esportiva como sendo a comercialização de práticas pertencentes à cultura esportiva.

O referido termo é também mais uma discussão relacionada às principais características e tendências presentes na sociedade contemporânea. De acordo com Pires (2000), vivemos numa sociedade tendenciosa voltada para o discurso pautado na globalização/espetacularização do esporte pela chamada indústria cultural. Nesse caso, devemos entender a indústria cultural como um negócio com finalidades de lucro, cujo desenvolvimento ocorre à medida que as exigências intelectuais do seu consumidor são rebaixadas, facilitando o acesso de todos à sua lógica e estrutura.

É nessa lógica perversa do sistema que rege a nossa sociedade que o esporte acaba se tornando uma espécie de negócio e a sua mercadorização, de acordo Bracht (2005), está especialmente relacionada ao desenvolvimento dos meios de comunicação de massa, bem como com a relação de interdependência entre ambos. Destaque para a televisão como principal veículo de comunicação nesse processo, cuja característica principal é a espetacularização.

Nesse contexto, Pires (2000) sinaliza os altos investimentos da mídia (com ênfase na mídia televisiva) na exploração do mercado consumidor, na banalização da cultura - destacando, nesse caso, a cultura esportiva - e no apelo exacerbado na espetacularização do esporte. O referido autor também analisa o esporte como a principal tendência da indústria cultural, que é a "sua transformação em mercadoria e elemento de colonização do tempo livre dos consumidores" (PIRES, 2000, p. 48).

Através do pensamento de Betti (1998), é possível entender como a mídia televisiva age nesse processo:

Na linha de frente dos posicionamentos em torno da televisão como componente da 'cultura de massa', ou 'indústria cultural', situam-se os que lhe atribuem uma função conservadora e alienante, tendo em vista que contribui para a dominação das massas, dirigindo e cerceando a

Pensar a Prática, Goiânia, v. 17, n. 3, p. 865-877, jul./set. 2014 
consciência das pessoas, e para a reprodução da cultura como mercadoria no processo capitalista. [...] Ela confunde realidade e imagem, e contribui para a 'perversão da formação', ao dispensar a mediação conceitual, mesmo a da fala, que se torna simples acessório das imagens. A linguagem-imagem da televisão compõe-se de estereótipos que despertam e representam as imagens do inconsciente do telespectador, e assim demonstram como devem comportar-se de acordo com os desejos do sistema (p. 40).

Uma questão muito importante apresentada por Betti (1998) é que o espectador - que com o advento da televisão tornou-se telespectador - tornou-se a figura mais importante para que o esporte se transformasse numa mercadoria que gera milhões de dólares em todo o mundo. Isso porque é esse indivíduo quem financia esse esquema, pagando para assistir aos eventos esportivos que são transmitidos pelos canais de TV. Além disso, percebe-se que no processo de mercadorização, o esporte tornou-se algo banal ao qual tudo pode ser associado, ou definido como esportivo. A mercadorização tornou o esporte uma janela de oportunidades para se vender qualquer coisa.

[...] encontramos no anúncio publicitário, condensado em poucos segundos, o espetáculo, a falação, a nostalgia, o cotidiano, a globalização, a velocidade, a ação, a emoção do esporte. Pneu, remédio, cartão de crédito, cerveja, refrigerante, automóvel, pasta dental, correios, leite, assinatura de jornal, flocos de milho, postos de combustível, sorvete, banco, companhia telefônica, perfume, desodorante, papel para xerox, pomada analgésica, televisor, aparelho de som, batata frita, cimento, freios para carro, cigarro, açúcar, canos de PVC. Não são apenas tênis e bolas, o esporte pode vender tudo (BETTI, 1998, p. 171).

A banalização da cultura esportiva é justamente a consequência de uma ideologia imposta pela mídia na construção dos sentidos/significados atribuídos ao esporte. A indústria cultural estabelece valores mediante uma semicultura, manipulando a consciência humana e incorporando estereóti$\operatorname{pos}^{4}$ para que sejam aceitos e reproduzidos de acordo com o que ela quer,

4 Tipo comum; inalterável, padrão. Segundo Betti (1998), é a linguagem-imagem da televisão que demonstra como o telespectador deve comportar-se de acordo os desejos do sistema.

Pensar a Prática, Goiânia, v. 17, n. 3, p. 865-877, jul./set. 2014 
em benefício de seu maior interesse: submeter o ser humano a uma condição de consumidor. Nesse contexto, como consequência da mercadorização presente na estrutura da cultura esportiva, ao que nos parece ser uma estratégia da própria mídia, percebe-se a popularização de diversas modalidades esportivas na sociedade, dentre elas, o $M M A$.

O termo popularização pode ser compreendido como algo relativo à população, uma derivação de popular que também pode significar público, notório, conhecido e democrático. De acordo o Dicionário Houaiss da Língua Portuguesa, popularização é uma derivação do termo popularizar, que significa tornar-se conhecido ou estimado por muitas pessoas; divulgado; ganhar aceitação do povo. Sendo assim, pode-se, também, considerar popularização como tudo o que é ou foi comum, presente no cotidiano de alguém ou de várias pessoas.

Apoiando-se nos escritos de Adorno e Horkheimer (1985) é possível entender que o conceito de popularização está relacionado à massificação da cultura, mediante os "clichês" da indústria cultural. Todo esse processo refere-se ao mercado consumidor, em que a indústria cultural padroniza gostos e preferências às massas sem que os indivíduos percebam. Um exemplo parecido ocorre no gosto popular pelo cinema e pelas telenovelas, em que a ficção e a realidade se misturam, confundindo a emoção muitas vezes vivida pelos telespectadores, causando a impressão de que o que acabaram de ver na televisão seja um prolongamento da vida cotidiana.

Outro exemplo de padronização está presente nas expressões das falas dos personagens da TV. Quando uma expressão é repetidamente divulgada na mídia, evidentemente ela se propaga e todos a utilizam, tornando-a popular. "A repetição universal dos termos adotados pelas várias determinações torna estas últimas de qualquer modo familiares" (ADORNO, 2002, p. 42).

A popularização também é consequência da universalização da cultura destinada ao consumo em larga escala. Pires (2000) sinaliza a sociedade contemporânea como uma sociedade globalizada e destaca a relevância da mídia, onde a cultura está sujeita à mundialização. $\mathrm{O}$ autor destaca ainda que as manifestações mais antigas destinadas ao entretenimento, como a música e o esporte, não têm como se abstrair da difusão dos meios de comunicação de massa.

Betti (1998) refere-se ao processo de popularização da cultura mediante a indústria cultural dizendo que:

[...] a presença das massas é hoje evidente em todas as dimensões da vida, $[. .$.$] os bens culturais estão agora à dis-$ posição de todos, por intermédio da televisão, jornal, rá-

Pensar a Prática, Goiânia, v. 17, n. 3, p. 865-877, jul./set. 2014 
dio, etc, $[\ldots]$ estamos vivendo numa época de alargamento da área cultural, na qual se realiza a circulação de uma arte e de uma cultura 'popular'(p. 46).

Nesse caso, é possível perceber que a mídia pode "democratizar" qualquer manifestação cultural e torná-la algo muito comum no dia a dia da sociedade. De acordo com Pires (2000), a sociedade atual é marcada pelo grande domínio dos meios de comunicação de massa (mídia), cuja função é efetivada mediante a disseminação de informações e pela instantaneidade como elas alcançam qualquer esfera do planeta.

No Brasil, por exemplo, existem muitas manifestações da cultura que se tornaram práticas popularizadas. Para ratificar esse argumento, Pires (2000) menciona o rodeio como uma manifestação da cultura esportiva que se tornou uma prática popularizada no Brasil e passou a representar um novo processo de "ruralidade" no país:

[...] de autêntica manifestação popular enraizada nas sociedades rurais de alguns Estados, passou a elemento representativo e aglutinador da nova ruralidade brasileira, incluindo diferentes setores da cultura de consumo, na medida em que agregou os códigos e signos de uma cultura mundializada, fornecidos pela mídia (PIMENTE, 1997 apud PIRES, 2000, p. 28).

É possível compreender o processo de popularização na sociedade contemporânea como algo inerente ao consumo, sendo uma efetiva estratégia da indústria cultural para atender aos interesses do sistema. Portanto, popularizar as práticas da cultura esportiva, tornou-se algo essencial nesse processo.

[...] trata-se de uma parceria indissolúvel e com tendência a crescer, vez que, se a TV populariza as modalidades, tornando-as mercadoria bem aceita no mercado mundial, também o esporte proporciona benefícios para a TV (POZZI, 1999 apud PIRES, 2000, p. 53).

Com base nos escritos de Pires (2000), acredita-se que a popularização do $M M A$ é consequência do processo de universalização cultural, mediante a espetacularização esportiva numa dimensão globalizada, graças às manobras tecnológicas da mídia. A ideia de Pires é ratificada por Alvarez e Marques (2011), quando os referidos autores sinalizam que vivemos num mundo cada vez mais globalizado, marcado por um processo de hibridiza- 
ção cultural, e que o MMA é fruto desse processo, a começar pelo termo Artes Marciais Misturadas.

As constantes evidências dessa prática corporal pela mídia, destacando-se a programação especializada que vende informações sobre o discurso esportivo, denominadas mídias esportivas, como as colunas destacadas nos jornais impressos, telejornais esportivos, comunidades virtuais na Internet, blogs, etc., que divulgam fatos e notícias sobre o $M M A$ dando-lhe ênfase, contribuem para que a referida prática torne-se cada vez mais presente no cotidiano das pessoas e adquira uma considerável popularidade.

A veiculação das lutas pela mídia e a consolidação do $M M A$ como fenômeno esportivo "universalizado" podem ser estimadas como uma consequência intencional para atender aos interesses do sistema (expansão da lógica capitalista). Assim, a popularização do $M M A$ é inerente à "cultura massificada" destinada ao consumo e é consequência do poder de persuasão da mídia, mediante a mercadorização do esporte pelo viés da espetacularização. Nesse contexto, a mídia se estabelece, determinando padrões culturais que são normalmente aceitos pela sociedade.

\section{Considerações finais}

O presente estudo buscou analisar a relação da mídia com o esporte, no intuito de compreender como acontece o processo de popularização do $M M A$, e destacou a mercadorização como um componente essencial nesse processo. Pôde-se constatar que os meios de comunicação de massa têm exercido considerável influência na disseminação de mensagens sobre o esporte, destacando, sobretudo, a mídia televisiva como um dos principais componentes desse processo.

Este estudo revelou também que o $M M A$ tornou-se um fenômeno esportivo de relevante notoriedade na sociedade e que o seu contexto histórico é constituído por interesses políticos, sociais e, sobretudo, econômicos. A sua função é servir aos interesses da lógica do espetáculo, contribuindo com o "fetichismo" da indústria cultural, cuja função é ratificar a sua ideologia destinada ao consumo.

A partir das reflexões realizadas com a análise da literatura, podemos afirmar que o grande envolvimento das pessoas com o $M M A$ é consequência da persuasão da mídia através da mercadorização esportiva, cujo viés é o apelo à espetacularização, uma vez que o referido esporte de combate tornou-se um atrativo para a venda de produtos e serviços, o que tem contribuído com a sua popularização na sociedade.

Contudo, sugere-se que sejam feitas outras investigações sobre o tema, envolvendo também algumas questões relacionadas à utilização da 
mídia para vender a ideia de ascensão socioeconômica mediante o sucesso na prática esportiva/MMA, e a espetacularização esportiva a partir da construção da imagem dos heróis esportivos, visando ampliar os estudos sobre esse processo.

\title{
MEDIA, SPORT COMMODIFICATION AND MOVEMENT OF MMA POPULARIZATION
}

\begin{abstract}
This current study analyses the relationship between media and sport in the MMA popularization process in the society, in a context which has capitalism as socialeconomic order. Firstly, a discussion with the literature was established in order to understand the sport phenomenon and how it fits in the contemporary society. This stage, eminently theoretical, has provided subsidies to elucidate questions that diffuse through the vehement MMA phenomenon growing and its constant evidence in the massive communication media. As a result, it was noticed that MMA popularization in the society is related to media persuasion, by the sport commodification process.
\end{abstract}

Keywords: Media. MMA. Sport Commodification. Popularization.

\section{MEDIA, MERCANTILIZACIÓN DEL DEPORTE Y MOVIMIENTO DE POPULARIZACIÓN DE MMA}

\section{Resumen}

Este estudio tiene como objetivo analizar la relación entre los medios y el deporte en el proceso de popularización de la $M M A$ en la sociedad, en un contexto que el capitalismo económico-social. Inicialmente, se trató de establecer un diálogo con la literatura, con el fin de entender el fenómeno de los deportes y la forma en que está configurado en la sociedad contemporánea. Este paso, eminentemente teórica, concedió subvenciones para aclarar algunas cuestiones que impregnan el crecimiento ferviente del fenómeno $M M A$ y de las pruebas constantes en los medios de comunicación de masas. Como resultado, se encontró que la popularidad de las $M M A$ en la sociedad está ligada a la persuasión de los medios de comunicación, a través del proceso de mercantilización del deporte.

Palabras-claves: Media. MMA. Mercantilización del Deporte. Popularización.

Pensar a Prática, Goiânia, v. 17, n. 3, p. 865-877, jul./set. 2014 


\section{Referências}

ADORNO, Theodor W. Indústria cultural e sociedade. Seleção de textos Jorge Mattos Brito de Almeida. Tradução: Juba Elisabeth Levy et al. - São Paulo. Paz e Terra, 2002.

ADORNO, T. W. \& HORKHEIMER, M. A indústria cultural: o esclarecimento como mistificação das massas. In: Dialética do esclarecimento: fragmentos filosóficos. Tradução: Guido Antônio de Almeida. Rio de Janeiro: Jorge Zahar ED, 1985.

ALVAREZ, Fábio de Lima e MARQUES, José Carlos. Breves Questionamentos Sobre o Fenômeno Midiático do MMA - Mixed Martial Arts (Artes Marciais Mistas): uma Proposta de Estudo. In: Anais [Da] Intercom Sociedade Brasileira de Estudos Interdisciplinares da Comunicação. XXXIV Congresso Brasileiro de Ciências da Comunicação - Recife, PE - 2 a 6 de setembro de 2011.

BETTI, Mauro. Janela de Vidro: esporte, televisão e educação física. Campinas: Papirus, 1998.

BRACHT, Valter. Sociologia crítica do esporte: uma introdução. (Coleção educação física), 3.ed. Ijuí: Ed. Unijuí, 136 p. 2005.

HOUAISS, Antônio (1915-1999) e VILLAR, Mauro de Salles (1939). Minidicionário Houaiss da Língua Portuguesa. Elaborado no Instituto Antônio Houaiss de Lexicografia e Banco de Dados da Língua Portuguesa S/C Ltda.3. ed. ver. E aum.- Rio de Janeiro: Objetiva, 2008.

LEITE, Werlayne Stuart Soares. Ilusão em massa: o papel da mídia no esporte. http://www.efdeportes.com/ Revista Digital - Buenos Aires - Año 13 - $\mathrm{N}^{\mathrm{o}} 123$ - Agosto de 2008.

PIRES, Giovani De Lorenzi. A Educação Física e o Discurso Midiático: abordagem crítico-emancipatória em pesquisa-ação no ensino de graduação. Campinas, SP, 2000.

TOREZANI, Julianna Nascimento. A Transmissão dos Eventos da UFC pela Rede Globo: uma análise pelas Teorias de Construção Social. In: Anais [Da]. Intercom - Sociedade Brasileira de Estudos Interdisciplinares da 
Comunicação. XIV Congresso de Ciências da Comunicação na Região Nordeste - Recife - PE - 14 a 16/06/2012.

Recebido em: 11/03/2014

Revisado em: 10/04/2014

Aprovado em: 06/05/2014

Endereço para correspondência:

elgeboh@yahoo.com.br

Vamberto Ferreira Miranda Filho

Universidade do Estado da Bahia, DCH - campus IV.

Rua Dr. J. J. Seabra, n. 158,

Estação

44700-000 - Jacobina, BA - Brasil

Pensar a Prática, Goiânia, v. 17, n. 3, p. 865-877, jul./set. 2014 